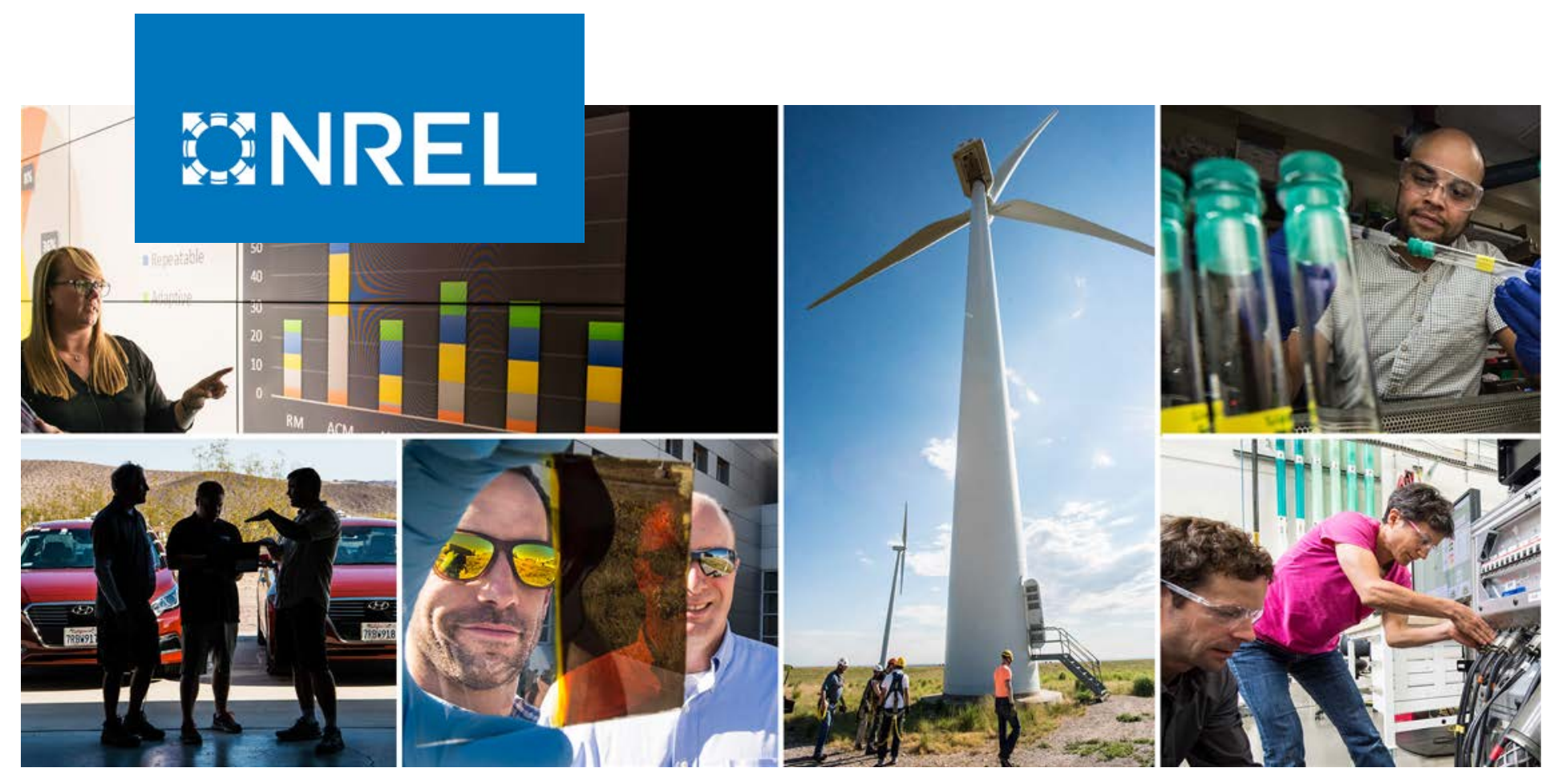

\title{
Up-Tower Investigation of Main Bearing Cage Slip and Loads
}

Roger Bergua Archeli, ${ }^{1}$ Jon Keller, ${ }^{1}$ Olle Bankestrom, ${ }^{2}$ Mark Dunn, ${ }^{2}$ Yi Guo, ${ }^{1}$ Alicia Key, ${ }^{1}$ and Emma Young ${ }^{3}$

1 National Renewable Energy Laboratory

$2 S K F$

3 University of Denver

NREL is a national laboratory of the U.S. Department of Energy Office of Energy Efficiency \& Renewable Energy

Operated by the Alliance for Sustainable Energy, LLC

This report is available at no cost from the National Renewable Energy Laboratory (NREL) at www.nrel.gov/publications.
Technical Report

NREL/TP-5000-81240

December 2021 


\section{GHREL}

\section{Up-Tower Investigation of Main Bearing Cage Slip and Loads}

Roger Bergua Archeli, ${ }^{1}$ Jon Keller, ${ }^{1}$ Olle Bankestrom, ${ }^{2}$ Mark Dunn, ${ }^{2}$ Yi Guo, ${ }^{1}$ Alicia Key, ${ }^{1}$ and Emma Young ${ }^{3}$

1 National Renewable Energy Laboratory

$2 S K F$

3 University of Denver

\section{Suggested Citation}

Bergua Archeli, Roger, Jon Keller, Olle Bankestrom, Mark Dunn, Yi Guo, Alicia Key, and Emma Young. 2021. Up-Tower Investigation of Main Bearing Cage Slip and Loads.

Golden, CO: National Renewable Energy Laboratory. NREL/TP-5000-81240.

https://www.nrel.gov/docs/fy22osti/81240.pdf.

NREL is a national laboratory of the U.S. Department of Energy Office of Energy Efficiency \& Renewable Energy Operated by the Alliance for Sustainable Energy, LLC

This report is available at no cost from the National Renewable Energy Laboratory (NREL) at www.nrel.gov/publications.

Contract No. DE-AC36-08GO28308
Technical Report

NREL/TP-5000-81240

December 2021

National Renewable Energy Laboratory 15013 Denver West Parkway Golden, CO 80401

303-275-3000 • www.nrel.gov 


\section{NOTICE}

This work was authored in part by the National Renewable Energy Laboratory, operated by Alliance for Sustainable Energy, LLC, for the U.S. Department of Energy (DOE) under Contract No. DE-AC36-08GO28308. Funding provided by U.S. Department of Energy Office of Energy Efficiency and Renewable Energy Wind Energy Technologies Office. The views expressed herein do not necessarily represent the views of the DOE or the U.S. Government.

This report is available at no cost from the National Renewable Energy Laboratory (NREL) at www.nrel.gov/publications.

U.S. Department of Energy (DOE) reports produced after 1991 and a growing number of pre-1991 documents are available free via www.OSTI.gov.

Cover Photos by Dennis Schroeder: (clockwise, left to right) NREL 51934, NREL 45897, NREL 42160, NREL 45891, NREL 48097, NREL 46526.

NREL prints on paper that contains recycled content. 


\section{Acknowledgments}

This work was authored by the National Renewable Energy Laboratory, operated by Alliance for Sustainable Energy, LLC, under Contract No. DE-AC36-08GO28308 for the U.S. Department of Energy. Funding provided by the U.S. Department of Energy Office of Energy Efficiency and Renewable Energy Wind Energy Technologies Office. This work was also made possible by the contributions of SKF USA Inc. under Cooperative Research and Development Agreement (CRADA) CRD-17-702. The authors would also like to thank Mr. Scott Lambert for developing the solid body model of the main bearing housing. 


\section{List of Acronyms}

$\begin{array}{ll}\text { BPFO } & \text { ball pass frequency of the outer race } \\ \text { CRADA } & \text { Cooperative Research and Development Agreement } \\ \text { DVST } & \text { Design Verification Support Tool } \\ \text { DW } & \text { downwind } \\ \text { FFT } & \text { fast Fourier transform } \\ \text { GPa } & \text { gigapascal } \\ \text { GS } & \text { generator-side } \\ \text { Hz } & \text { hertz } \\ \text { IEC } & \text { International Electrotechnical Committee } \\ \text { ISO } & \text { International Organization for Standardization } \\ \text { Kg } & \text { kilogram } \\ \text { kN } & \text { kilonewton } \\ \text { kN·m } & \text { kilonewton-meter } \\ \text { LCOE } & \text { levelized cost of energy } \\ \text { Mm } & \text { millimeter } \\ \text { MW } & \text { megawatt } \\ \text { NREL } & \text { National Renewable Energy Laboratory } \\ \text { OpEx } & \text { operational expenditures } \\ \text { OR } & \text { outer ring } \\ \text { Rpm } & \text { revolutions per minute } \\ \text { RLIS } & \text { roller load-induced strain } \\ \text { RMS } & \text { root-mean-square } \\ \text { RS } & \text { rotor-side } \\ \text { SRB } & \text { spherical roller bearing } \\ \text { UW } & \text { upwind } \\ \text { UTC } & \text { universal time coordinated }\end{array}$




\section{Table of Contents}

Acknowledgments ........................................................................................................................ iii

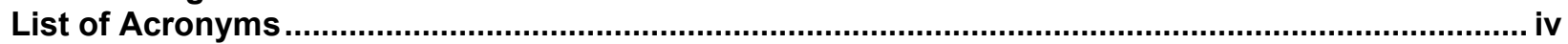

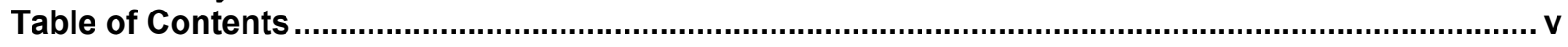

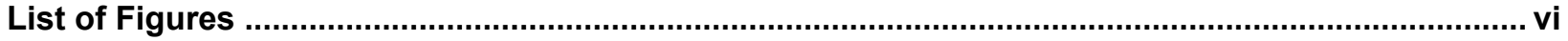

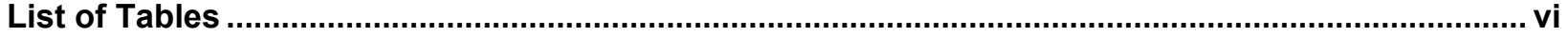

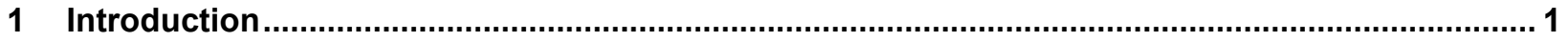

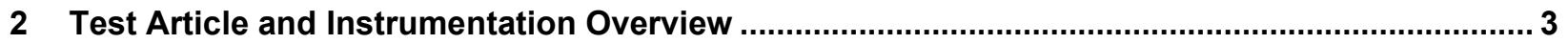

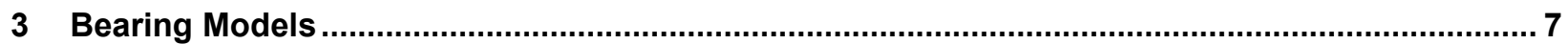

3.1 Analytical Model for Applied Bearing Loads ..................................................................... 7

3.2 Finite Element Model for Roller Loads and Stresses............................................................... 9

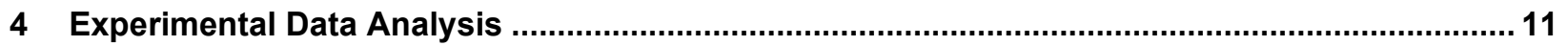

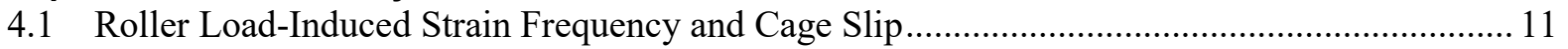

4.2 Roller Load-Induced Strain Magnitude and Tangential Strain .............................................. 13

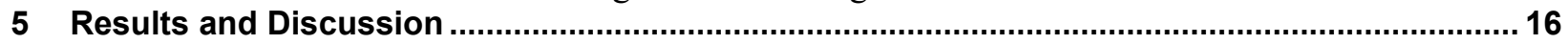

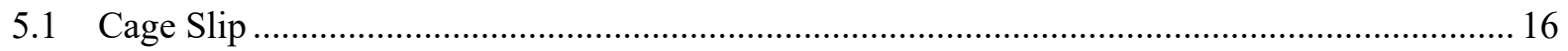

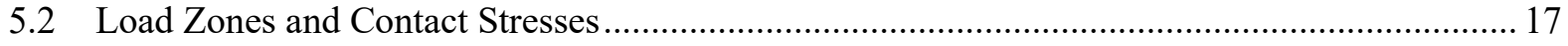

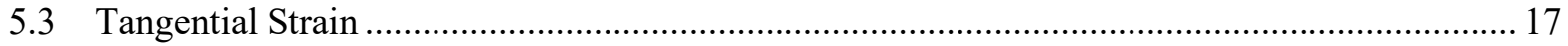

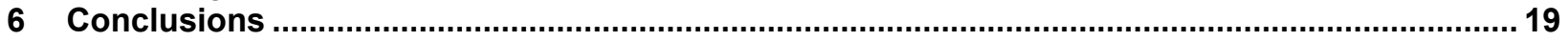

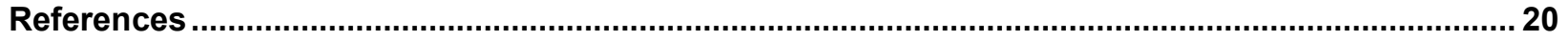




\section{List of Figures}

Figure 1. Winergy PEAB 4410.4 gearbox and SKF main bearing. Photo by Jonathan Keller, NREL 49044

Figure 2. SKF main SRB and DVST nodes (left) and other instrumentation (right). Photos by Jonathan Keller and Jerry Hur, NREL 49379 and 49959.

Figure 3. RS DVST node at the $0^{\circ}$ position prior to installation. Photo by Mark Dunn, NREL $65814 \ldots \ldots \ldots . .5$

Figure 4. Force balance diagram of the drivetrain ........................................................................ 7

Figure 5. Transmission3D finite element model of the main bearing with (left) and without (right) housing and bearing outer ring in the above cut-in condition ..................................................................... 10

Figure 6. Transmission3D finite element model of the main bearing with (left) and without (right) housing and bearing outer ring in the rated condition.

Figure 7. Example roller load-induced strain (RLIS) measurement for the $180^{\circ} \mathrm{GS}$ position in the time domain (left) and frequency domain (right) for the above cut-in condition ...................................... 12

Figure 8. All roller load-induced strain (RLIS) measurements in the time domain (left) and frequency domain (right) for the rated condition

gure 9. RMS of measured tangential strain at $0^{\circ}$ (upper left), $90^{\circ}$ (upper right), $180^{\circ}$ (lower left), and

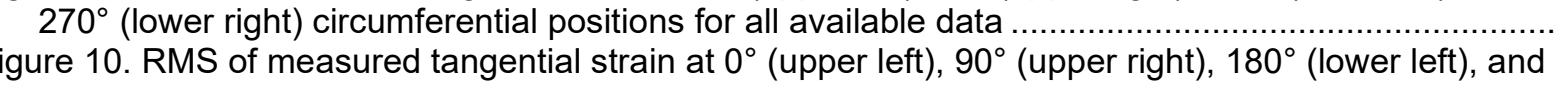
$270^{\circ}$ (lower right) circumferential positions for analyzed data.....

Figure 11. BPFO ratio for the $180^{\circ} \mathrm{GS}$ position

Figure 12. Bearing load zones (left) and contact stresses (right) in the above cut-in and rated conditions

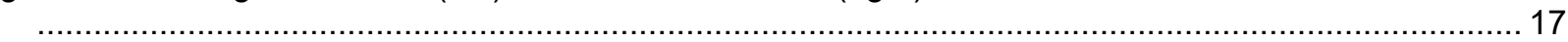

Figure 13. Tangential strains in above cut-in (left) and rated (right) conditions.................................... 18

\section{List of Tables}

Table 1. DVST Node Sensors and Measurements 


\section{Introduction}

Wind plant operational expenditures (OpEx) remain an appreciable contributor to the overall cost of wind energy, with a capacity-weighted average of $\$ 44$ per kilowatt per year for land-based wind plants (Wiser, Bolinger, and Lantz 2019) and approximately three times that cost offshore (Stehly, Beiter, and Duffy 2020). OpEx represent a sizable and potentially growing share of the levelized cost of energy (LCOE), especially as wind's LCOE declines because of lower up-front costs and better performance. Recent data suggest wind plant OpEx can account for $25 \%$ to more than 35\% of the LCOE of both land-based and offshore wind (Wiser, Bolinger, and Lantz 2019; Carroll et al. 2017). Approximately half of land-based plant OpEx are associated directly with turbine operation and maintenance (Wiser, Bolinger, and Lantz 2019). Turbine operation and maintenance costs therefore represent the single largest component of wind plant OpEx and the primary source of potential operation and maintenance cost reductions. Total OpEx reductions could represent $10 \%$ or more of the expected reduction in land-based wind LCOE (Wiser, Bolinger, and Lantz 2019; Stehly, Beiter, and Duffy 2020) and as much as $40 \%$ of the expected reduction for fixed-bottom, offshore wind plants if improved vessel accessibility and remote maintenance strategies are included (Stehly, Beiter, and Duffy 2020).

In most wind turbines, one or more rolling element bearings are used to support the rotor weight, thrust, and depending on the bearing type a portion of the rotor pitch and yaw moments. A variety of bearing types and combinations can fulfill this function (Chovan and Fierro 2021). These bearings are typically called the "main" bearings and can either be located in a dedicated housing or integrated within the gearbox itself or a direct-drive generator. Main bearings do not have an application-specific design standard and are typically rated with respect to International Organization for Standardization (ISO) standards, technical specifications, or supplier specifications (Keller et al. 2021; Nejad et al. 2021). Premature main bearing failures can be a significant operation and maintenance cost (Hart et al. 2020), although failure rates can vary between populations (e.g., land-based or offshore, direct-drive or geared, site-to-site, drivetrain mounting style). Unlike most gearboxes, main bearings typically cannot be repaired uptower and often require crane removal, which results in appreciable downtime. Most failures are related to progressive wear stemming from micropitting, smearing, scuffing, skidding, or fretting rather than fatigue (Kotzalas and Doll 2010; Brake 2013; Greco et al. 2013; Hart et al. 2019; Hart et al. 2020; Chovan and Fierro 2021; Keller et al. 2021). Failure rates in some populations can be as high as $20 \%-30 \%$ in as little as 6-10 years (Brake 2013; Sethuraman, Guo, and Sheng. 2015; Hart et al. 2019), though they were designed for a rating life exceeding 20 years (Liang, An, and Liu. 2013).

Main bearing loads, including those induced by gravity, aerodynamic rotor thrust and side loads, and pitch and yaw moments, are the result of interactions between the rotor and the complex wind field in which it is operating (Hart et al. 2020; Hart 2020). The effect of axial motion on main bearing wear of an instrumented spherical roller main bearing in the General Electric 1.5megawatt (MW) SLE model turbine at the National Renewable Energy Laboratory (NREL) Flatirons Campus was recently examined. The axial velocity of the rollers compared to their rolling speed was found to be negligible and thus not expected to influence lubricant film thickness (Guo et al. 2021). In this report, additional measurements of roller load-induced behavior on the same wind turbine are described and used to examine typical roller loads, outer ring strain, and other factors that might impact main bearing health, such as, cage slip. These 
parameters are useful for comparison with bench-level tests of bearing contact conditions that have been shown to contribute to premature wear and fatigue (Gould et al. 2021). 


\section{Test Article and Instrumentation Overview}

The test article is a specially instrumented, commercial 1.5-MW drivetrain. The instrumented portion of the drivetrain consists of a SKF main bearing, described herein, and a Winergy 4410.4 gearbox (Keller and Lambert 2018) as shown in Figure 1 prior to installation of the drivetrain in the General Electric 1.5 SLE turbine at the NREL Flatirons Campus.

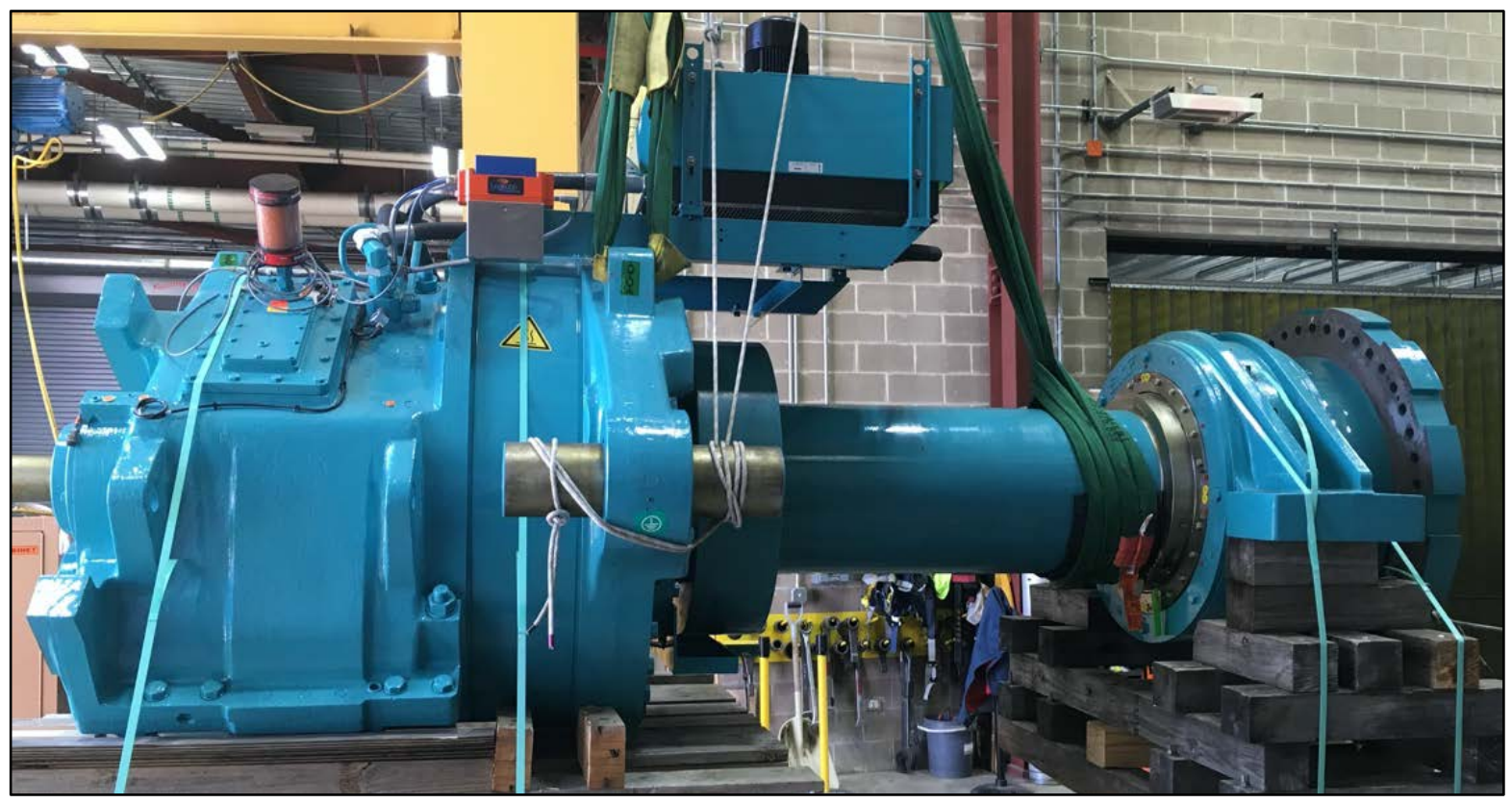

Figure 1. Winergy PEAB 4410.4 gearbox and SKF main bearing. Photo by Jonathan Keller, NREL 49044

The main bearing is an SKF model BS2-8115/C2H spherical roller bearing (SRB) lubricated with SKF Winter Grade LGWM2 grease. Although it is similar to a standard 240/600 ECA/W33 double-row SKF Explorer series SRB with a bore diameter of 600 millimeters $(\mathrm{mm})$ and width of $272 \mathrm{~mm}$, the installed main bearing has only 28 rollers in each row. Its design was updated to optimize internal geometry specific to the turbine loads, use a new cage design and material, provide better sealing through a customized seal design, and improve lubrication with an automated relubrication system (Raju and Bankestrom 2017; James 2018). The bearing cage is driven by both roller rows simultaneously. This bearing now has the commercial designation $240 / 600 \mathrm{BC}$ with a basic static load rating of 16,300 kilonewton $(\mathrm{kN})$, mass of 520 kilograms $(\mathrm{kg})$, and a reference shaft speed of 20 revolutions per minute (rpm) (SKF 2021). Additionally, the bearing has a fatigue load limit of $1,100 \mathrm{kN}$, a basic dynamic load rating of $8,502 \mathrm{kN}$, and a "limiting value" of 0.3 (i.e., limiting value, $e$, of the axial-to-radial load ratio for the applicability of different dynamic radial and axial load factors, $X$ and $Y$, per rating life calculations in ISO 281). The main bearing, auxiliary equipment, and some instrumentation were contributed to the project by SKF USA under cooperative research and development agreement CRD-17-702. The main bearing and associated instrumentation are shown in Figure 2.

Of specific interest to the research program is the operational environment of the main SRB. The primary subject of this report is the examination of measurements from the design verification support tool (DVST) nodes provided by SKF and shown in Figure 2. Eight DVST nodes, split 
evenly on the rotor-side (RS) and generator-side (GS) of the main SRB are installed at four locations around the bearing circumference at $0^{\circ}, 90^{\circ}, 180^{\circ}$, and $270^{\circ}$ when viewed from the RS. Each DVST node measures tangential strain, acoustic emission, axial vibration, and temperature from a point on the side face of the stationary outer ring (OR) (Keller 2018). The rotational speed of the main shaft is transmitted by a ninth DVST node and measured by a separate tachometer. Tangential strain is the primary measurement examined in this report. Acoustic emissions and temperatures will be the subject of future studies. Axial vibration is primarily used for bearing condition monitoring, so it is also not examined in this report. The proximity sensors, also shown in Figure 2, were previously described and examined (Guo et al. 2021), so they are not discussed further within this report. Stray electrical currents flowing through the main bearing were also examined and described (Keller, Guo, and Sethuraman 2019); however, work is ongoing to understand their potential effect on main bearing reliability (Gould et al. 2021).
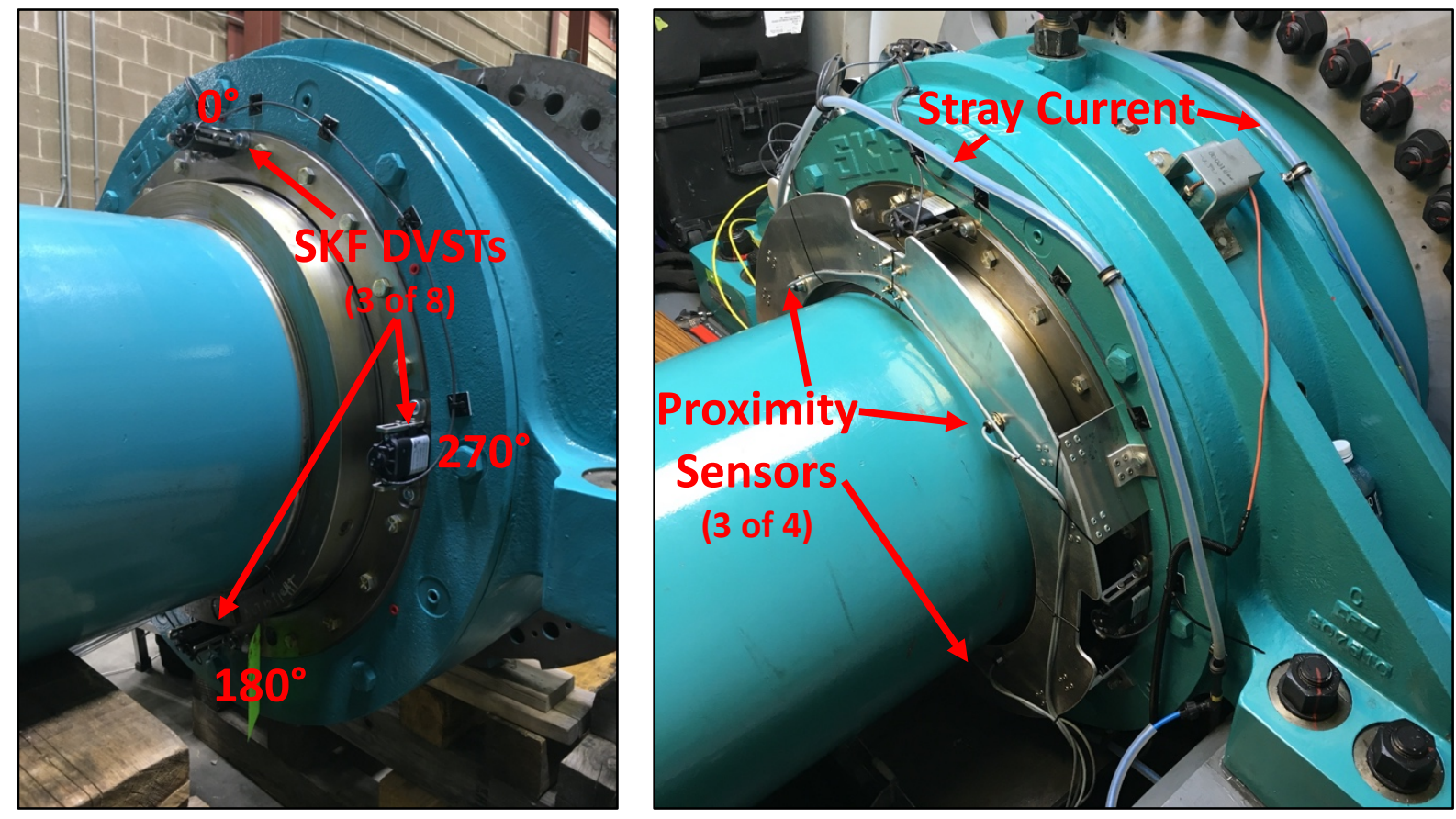

Figure 2. SKF main SRB and DVST nodes (left) and other instrumentation (right). Photos by Jonathan Keller and Jerry Hur, NREL 49379 and 49959

As shown in Figure 2 and Figure 3, each DVST node is bolted to a specially machined recess on the bearing cover. At each DVST node location at a radius of $411 \mathrm{~mm}$, two holes are drilled through the cover. When the DVST node is mounted, its two spring-loaded legs contact the side face of the stationary bearing OR. The tip of one leg measures the tangential strain through a contact strain gauge, while sensors on the other tip measure acoustic emission, vibration, and temperature. Ideally, the contact force and friction between the legs and the side face of the stationary OR are sufficient to measure these quantities and prevent external contamination, including contamination from bearing grease. 


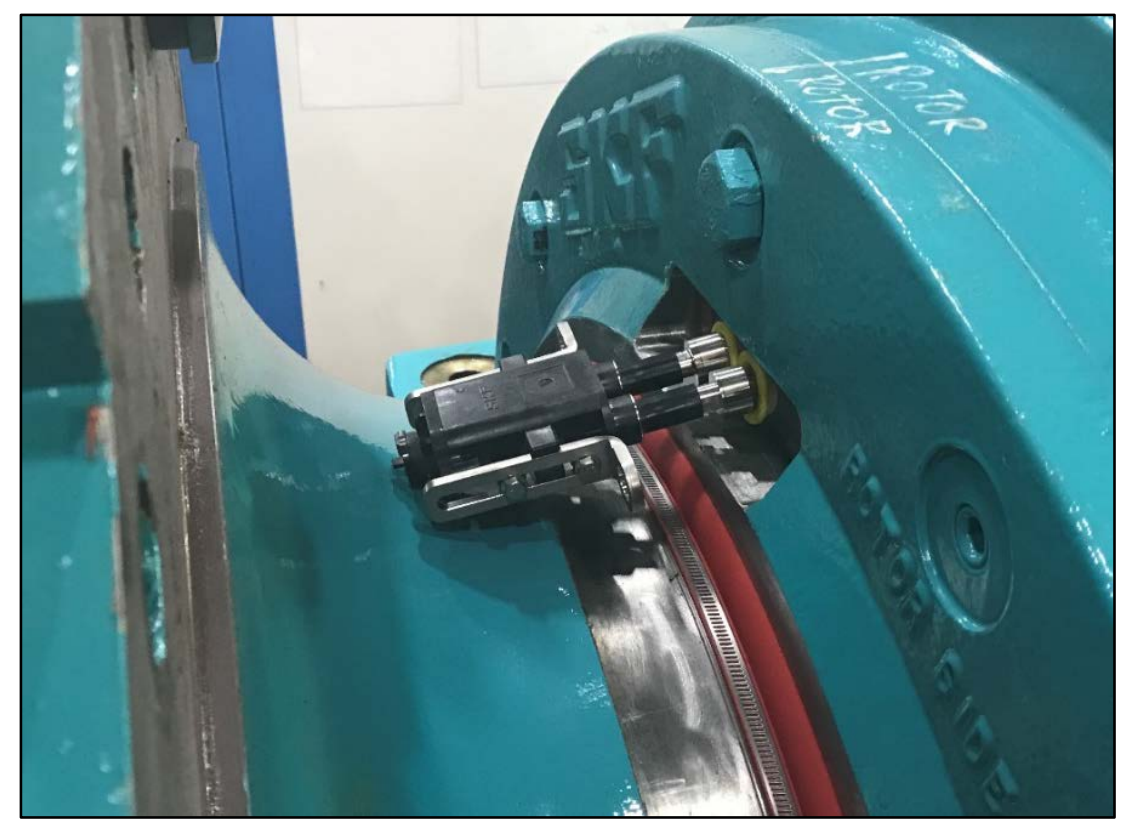

Figure 3. RS DVST node at the $0^{\circ}$ position prior to installation. Photo by Mark Dunn, NREL 65814

The acquisition of DVST node measurements can be configured, but not all measurements can be simultaneously acquired. For this test, the quantities in Table 1 are acquired at times when the main shaft rotational speed is between specified minimum and maximum rotational speeds for a duration of 32 seconds (s) at 256 hertz (Hz), typically once every 5 minutes. Additionally, DVST node measurements can be commanded by the user. The DVST node and main shaft rotational speed measurements are recorded by a personal computer located in the nacelle with the corresponding time for accurate data timestamping and system clock setting, which is especially useful for correlation with the other collected meteorological and turbine operational parameters. DVST node data are transferred via cellular connection to a cloud server.

Table 1. DVST Node Sensors and Measurements

\begin{tabular}{cccccc}
\hline $\begin{array}{c}\text { Signal } \\
\text { Name }\end{array}$ & $\begin{array}{c}\text { Circumferential } \\
\text { Position }\end{array}$ & $\begin{array}{c}\text { Temperature } \\
\left({ }^{\circ} \mathbf{C}\right)\end{array}$ & $\begin{array}{c}\text { Axial Acceleration } \\
\text { Enveloping } \\
(\mathbf{g})\end{array}$ & $\begin{array}{c}\text { Tangential } \\
\text { Strain } \\
(\mu \varepsilon)\end{array}$ & $\begin{array}{c}\text { Acoustic Emission } \\
\text { Enveloping } \\
(-)\end{array}$ \\
\hline 12_UW & $0^{\circ} \mathrm{RS}$ & $\mathrm{X}$ & & & $\mathrm{X}$ \\
3_UW & $90^{\circ} \mathrm{RS}$ & $\mathrm{X}$ & $\mathrm{X}$ & \\
6_UW & $180^{\circ} \mathrm{RS}$ & $\mathrm{X}$ & & & \\
9_UW & $270^{\circ} \mathrm{RS}$ & $\mathrm{X}$ & $\mathrm{X}$ & \\
12_DW & $0^{\circ} \mathrm{GS}$ & $\mathrm{X}$ & & $\times$ & \\
3_DW & $90^{\circ} \mathrm{GS}$ & $\mathrm{X}$ & & $\mathrm{X}$ & \\
6_DW & $180^{\circ} \mathrm{GS}$ & $\mathrm{X}$ & & $\times$ & \\
9_DW & $270^{\circ} \mathrm{GS}$ & $\mathrm{X}$ & & $X$ & \\
\hline
\end{tabular}

Additional instrumentation on the meteorological tower and wind turbine also provides measurements to understand the main bearing environment. Routine meteorological tower 
measurements are air temperature, pressure, humidity, and wind speed and direction at multiple heights. Routine turbine measurements are nacelle direction and, nacelle interior temperature; rotor speed; blade pitch angles; main shaft, tower, and blade loads; turbine power; and several supervisory control and data acquisition channels (Santos and van Dam 2015, Keller, Guo, and Sethuraman 2019). A Global Positioning System C-Series synchronization module records meteorological tower and turbine data with the corresponding time for accurate data timestamping and system clock setting. The measured data channels are then archived to the NREL network via an Ethernet connection. 


\section{Bearing Models}

To calculate the main bearing roller loads and strains, two different models are used. The first is an analytical model that describes the axial and radial loads applied to the main bearing, given the drivetrain characteristics and aerodynamic rotor forces and moments. With these applied loads, the second finite element/contact mechanics model determines individual roller loads, strains, and contact stresses. The following sections describe these two models.

\subsection{Analytical Model for Applied Bearing Loads}

A free-body diagram of the hub and drivetrain, expanded from previous work (Guo et al. 2021), is shown in Figure 4. In this report, only relatively simple, steady-state turbine operating conditions yielding these forces and moments are examined. Future work will consider more complex, time-varying aerodynamic loading. Because the main bearing is an SRB, it is assumed to react only axial and radial forces. The gearbox torque arms are also assumed to react only axial and radial forces. The radial forces on each torque arm resulting from torque can be ignored as they are equal and opposite. Further, the axial reaction loads on the main bearing and gearbox torque arms are represented as spring stiffnesses acting in a parallel arrangement. Finally, the reaction loads from the generator coupling are not considered because the stiffness of this coupling is several orders of magnitude less than the stiffnesses of the main bearing and bushings in the gearbox torque arms.

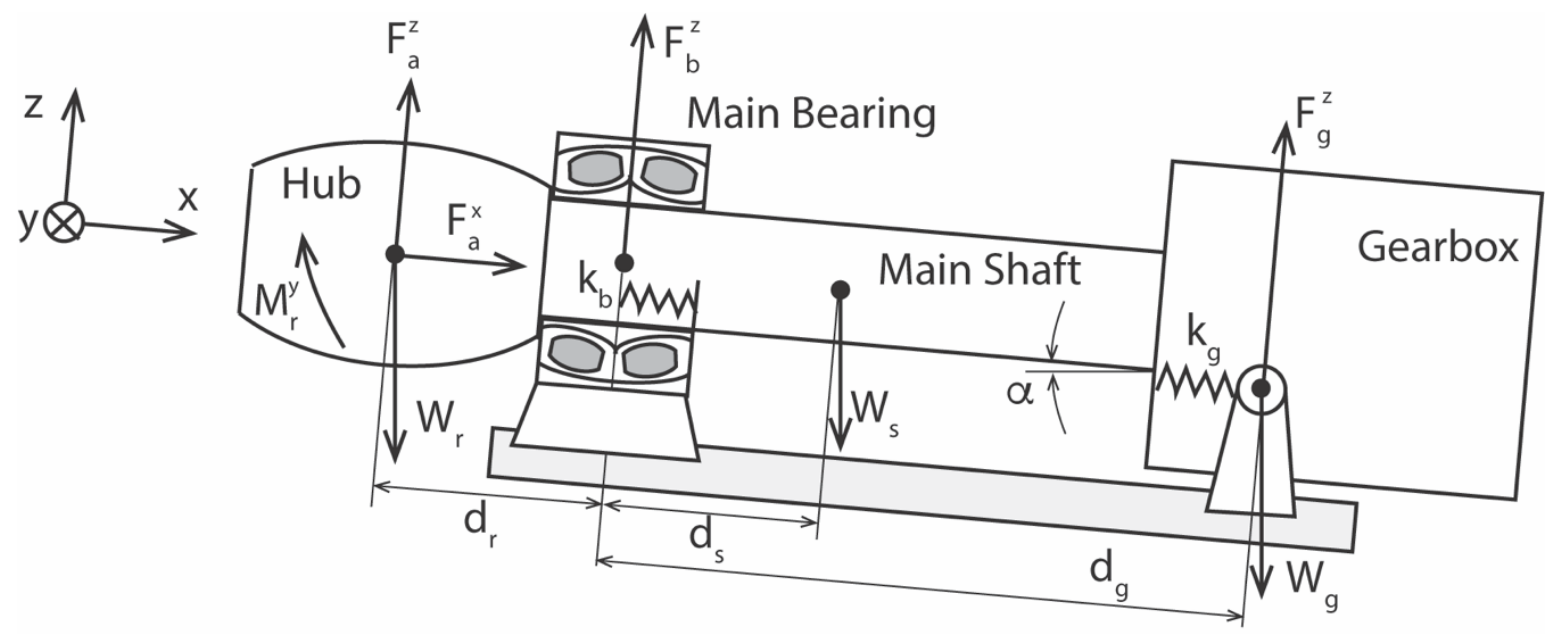

Figure 4. Force balance diagram of the drivetrain

With these assumptions, performing a force and moment balance about the main bearing yields the following equations of equilibrium

$$
\begin{aligned}
& \sum F^{\mathrm{x}}=F_{\mathrm{a}}^{\mathrm{x}}(t)+\left(W_{\mathrm{r}}+W_{s}+W_{\mathrm{g}}\right) \sin \alpha=\left(k_{\mathrm{b}}+2 k_{\mathrm{g}}\right)\left(x(t)+x_{\mathrm{r}}\right) \\
& \sum F^{\mathrm{z}}=F_{\mathrm{a}}^{\mathrm{z}}(t)+F_{\mathrm{b}}^{\mathrm{z}}(t)+F_{\mathrm{g}}^{\mathrm{z}}(t)-\left(W_{\mathrm{r}}+W_{\mathrm{s}}+W_{\mathrm{g}}\right) \cos \alpha=0 \\
& \sum M^{\mathrm{y}}=M_{\mathrm{r}}^{\mathrm{y}}(t)+F_{a}^{z}(t) d_{\mathrm{r}}-F_{g}^{z}(t) d_{\mathrm{g}}-\left(W_{\mathrm{r}} d_{\mathrm{r}}-W_{\mathrm{s}} d_{\mathrm{s}}-W_{\mathrm{g}} d_{\mathrm{g}}\right) \cos \alpha=0
\end{aligned}
$$


where $F_{\mathrm{a}}, F_{\mathrm{b}}$, and $F_{\mathrm{g}}$ are the aerodynamic rotor loads, main bearing reaction loads, and gearbox reaction loads, respectively; $t$ is time; $k_{\mathrm{b}}$ and $k_{\mathrm{g}}$ are the axial stiffnesses of the bearing and gearbox trunnion mounts, respectively; $x$ is the axial displacement of the drivetrain and $x_{\mathrm{r}}$ is its resting position; and $M_{\mathrm{r}}^{\mathrm{y}}$ is the rotor pitch moment. The superscripts $\mathrm{x}, \mathrm{y}$, and $\mathrm{z}$ represent the axial and two radial directions, respectively (illustrated in Figure 4.).

The mass of the rotor, main shaft, and gearbox are $31,700 \mathrm{~kg}, 5,000 \mathrm{~kg}$, and 14,000 kg, respectively (Guo et al. 2021), to yield the weights of each component $W_{\mathrm{r}}, W_{\mathrm{s}}$, and $W_{\mathrm{g}}$; the distances from the main bearing to the hub center $d_{\mathrm{r}}$, main shaft center $d_{\mathrm{s}}$, and gearbox trunnion $d_{\mathrm{g}}$, equal 1.90 meters $(\mathrm{m}), 0.94 \mathrm{~m}$, and $2.09 \mathrm{~m}$, respectively; and the drivetrain tilt angle $\alpha$ is $5^{\circ}$. Note that there are three equations with three unknowns: $x, F_{\mathrm{g}}$, and $F_{\mathrm{b}}$; however, the axial displacement of the drivetrain $x$ with respect to its resting position $x_{\mathrm{r}}$ can be solved independently of the other two equations with specified bearing and gearbox trunnion mount axial stiffnesses, $k_{\mathrm{b}}$ and $k_{\mathrm{g}}$ (Guo et al. 2021). Solving for the unknowns yields

$$
\begin{aligned}
& x(t)+x_{\mathrm{r}}=\frac{F_{\mathrm{a}}^{\mathrm{x}}(t)+\left(W_{\mathrm{r}}+W_{s}+W_{\mathrm{g}}\right) \sin \alpha}{k_{\mathrm{b}}+2 k_{\mathrm{g}}} \\
& F_{\mathrm{g}}^{\mathrm{z}}(t)=\frac{M_{\mathrm{r}}^{\mathrm{y}}(t)+F_{\mathrm{a}}^{\mathrm{z}}(t) d_{\mathrm{r}}-\left(W_{\mathrm{r}} d_{\mathrm{r}}-W_{\mathrm{s}} d_{\mathrm{s}}-W_{\mathrm{g}} d_{\mathrm{g}}\right) \cos \alpha}{d_{\mathrm{g}}} \\
& F_{\mathrm{b}}^{\mathrm{z}}(t)=-F_{\mathrm{a}}^{\mathrm{z}}(t)-F_{\mathrm{g}}^{\mathrm{z}}(t)+\left(W_{\mathrm{r}}+W_{\mathrm{s}}+W_{\mathrm{g}}\right) \cos \alpha
\end{aligned}
$$

In idling (i.e., nonoperating) conditions, the aerodynamic rotor loads and rotor moment are zero. In this condition $x \equiv 0$, and the resting position of the main bearing is slightly toward the GS from its geometric center, though both bearing rows are still loaded (Guo et al. 2021). The main bearing and gearbox reaction loads are simply a result of the rotor and drivetrain weights and respective moment arms and are $618 \mathrm{kN}$ and $-123 \mathrm{kN}$, respectively. That is, in idling conditions, the gearbox trunnion arms are holding the gearbox down. The main bearing reacts a large radial load of $618 \mathrm{kN}$ radially upward and a moderate axial load of $43 \mathrm{kN}$ upwind. With respect to the bearing, the applied loads are opposite in sign: the bearing is subject to a radial load of $618 \mathrm{kN}$ radially downward and an axial gravity load of $43 \mathrm{kN}$ downwind. The axial-to-radial load ratio of the main bearing in idling conditions is thus 0.07 . This is less than the value of $e$, yielding dynamic radial and axial load factors, $X$ and $Y$, of 1 and 2.25 and a dynamic equivalent radial load, $P_{\mathrm{r}}$, of $716 \mathrm{kN}$ per ISO 281.

Previous work examined the axial loads in both idling and low wind speed conditions. Above the cut-in wind speed and below a wind speed of approximately 5 meters per second $(\mathrm{m} / \mathrm{s})$, the turbine operates at a rotor speed of approximately $11 \mathrm{rpm}$. In this condition, the rotor aerodynamic thrust remains below $40 \mathrm{kN}$ (Guo et al. 2021). For the purposes of the analysis in this report, this operating condition is termed "above cut-in" and is useful because the DVST records data in this condition, but not in idling conditions.

To understand the main bearing loads in normal power production conditions, the rotor loads must also be accounted for through either experimental measurements or aeroelastic simulations. 
Rated operating conditions were previously observed at wind speeds of approximately $10-11 \mathrm{~m} / \mathrm{s}$, in which the maximum aerodynamic rotor thrust was estimated through both OpenFAST aero-servo-elastic simulations and tower load measurements to be just over $200 \mathrm{kN}$ (Guo et al. 2021). Combined with the axial gravity load, the maximum axial load applied to the main bearing could then be as high as $250 \mathrm{kN}$. The rotor moment was also estimated to be 150 kilonewton-meter $(\mathrm{kNm})$ using OpenFAST with a wind shear exponent of 0.2 in this rated condition per International Electrotechnical Commission Standard 61400-1. With these applied loads, the resulting bearing vertical reaction force reduces to $546 \mathrm{kN}$. Therefore, this radial load of $546 \mathrm{kN}$ combined with the axial load of $250 \mathrm{kN}$ is taken as the load case for the rated operating condition of the turbine as examined in this report. In this condition, the axial-to-radial load ratio is 0.46 . This is greater than the value of $e$, yielding dynamic radial and axial load factors, $X$ and $Y$, of 0.67 and 3.35 and a dynamic equivalent radial load, $P_{\mathrm{r}}$, of $1,205 \mathrm{kN}$ per ISO 281.

\subsection{Finite Element Model for Roller Loads and Stresses}

The Transmission3D software application implements a three-dimensional, contact-mechanics model (Advanced Numerical Solutions, 2021). Bearing contacts, including piece-wise clearance nonlinearities, are modelled with a hybrid of finite elements to predict far-field displacements and a Green's function model to predict displacements in the contact region. Known bearing clearances and the detailed roller and raceway geometries are included. The bearing housing provides structural support for the main bearing and is, therefore, included in the model. The bolt holes on the housing arms are constrained in the model as the boundary condition. The bearing rings are connected with the housing and main shaft through flexible joints. The finite element model computes bearing contact quasi-statically for different roller positions. The load cases described in Section 3.1 were applied to this model to calculate bearing contact loads over 10 steps of a ball pass period. The outputs include stresses and strains, roller loads, and deflections. The Transmission3D main bearing model and von Mises stresses in the above cut-in and rated conditions are illustrated in Figure 5 and Figure 6, respectively. As expected, in both cases the load zone is centered on the bottom, $180^{\circ}$ position, as the applied loads are dominated by the rotor weight. In the above cut-in condition, only a relatively small portion of rollers are loaded on both rows. However, because of the additional rotor thrust in the rated condition, all rollers on the downwind row support loads - even rollers at the top of the downwind row. Although all downwind rollers have the capability to support load, they do not necessarily do so in all operating conditions. Note that in each case, there are predicted stresses (and resulting strains) in the bearing rings and housing that extend beyond the span of the loaded rollers. 

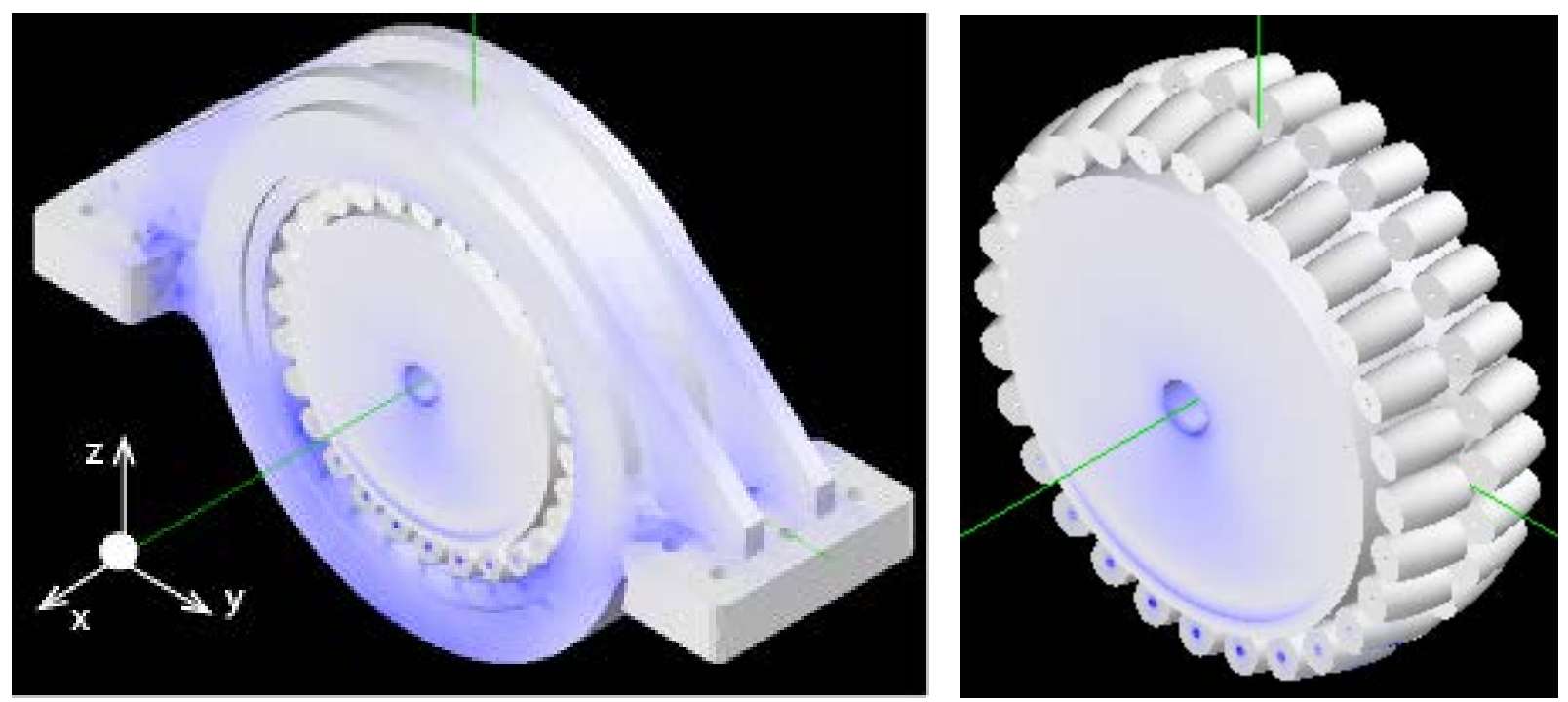

Figure 5. Transmission3D finite element model of the main bearing with (left) and without (right) housing and bearing outer ring in the above cut-in condition
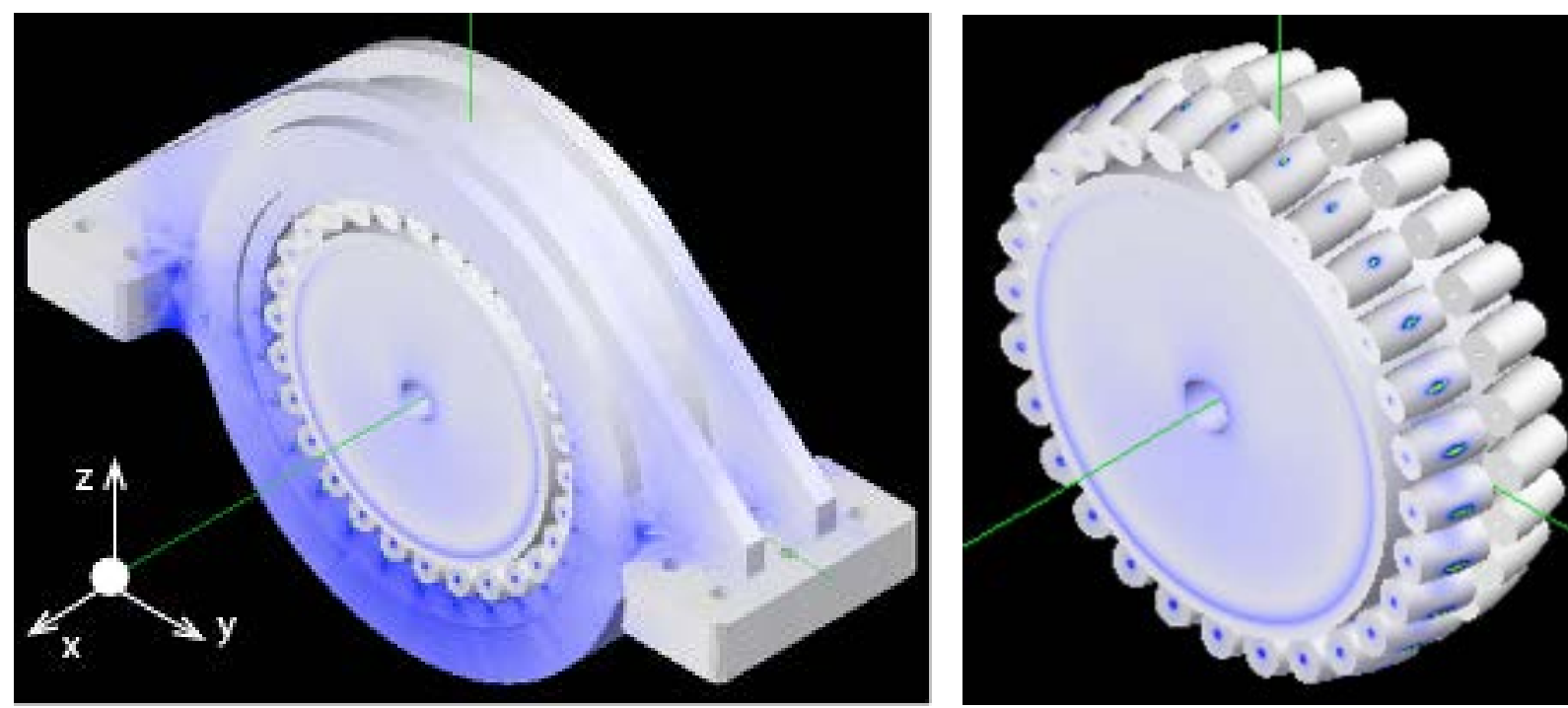

Figure 6. Transmission3D finite element model of the main bearing with (left) and without (right) housing and bearing outer ring in the rated condition 


\section{Experimental Data Analysis}

As described in Section 2, one quantity the DVST nodes measure is the tangential strain of the side face of the stationary bearing OR as each roller passes that point and deforms the ring. It is typically referred to as the roller load-induced strain (RLIS). Because the tangential strain is measured by a contact strain gauge, it only provides an accurate measurement of the change in strain as each roller passes. It does not provide a reliable measurement of the mean strain value over long periods of time. In previous work, the change in strain measurements was successfully used to examine bearing load zones and estimate roller loads and contact stresses for gearbox bearings (Guo and Keller 2018; Keller et al. 2018). Both the frequency and magnitude of the RLIS can be examined to investigate the bearing operating conditions as described in the following sections.

\subsection{Roller Load-Induced Strain Frequency and Cage Slip}

The measurement of the RLIS for a period of time can be used to determine the actual ball (or roller) pass frequency of the outer race (BPFO). The BPFO indicates the number of rolling elements that pass by a given point on the outer race (e.g., the sensor location) for a shaft revolution. By comparing the measured BPFO and the theoretical BPFO for pure rolling conditions based on the measured main shaft rotational speed, it is possible to determine if the bearing cage is rotating at the expected speed or slower than the expected speed. If it is slower than expected, then cage slip is occurring. For the SKF 240/600 BC bearing in pure rolling conditions, 12.705 rollers pass an arbitrary point on the outer race per shaft revolution (SKF 2021).

The bearing cage is driven by the rollers within the load zone. Therefore, cage slip occurs only when most of the rollers are slipping. However, even if the bearing cage is aligned with the theoretical speed, some rollers can still be slipping depending on a variety of factors, including the bearing load zone distribution, shaft speed, and lubricant characteristics. The aforementioned data analysis determines if the bearing cage is slipping, but not if the rollers are.

The RLIS measurements are $32 \mathrm{~s}$ in length and have a sampling frequency of $256 \mathrm{~Hz}$. Figure 7 (left) shows an example of the data recorded in the time domain for the highly loaded $180^{\circ} \mathrm{GS}$ position for the "above cut-in" condition. Because the $180^{\circ} \mathrm{GS}$ position is the most highly loaded resulting in large measured RLIS amplitudes, it is expected to be the best candidate to determine the actual BPFO. To determine the actual BPFO, the time waveform is postprocessed in the frequency domain by means of the fast Fourier transform (FFT) as shown in Figure 7 (right). The resulting frequency resolution in the spectrum is $0.0312 \mathrm{~Hz}$. Figure 7 (right) shows the BPFO fundamental frequency and the corresponding harmonics, denoted by dashed grey vertical lines. The vertical dashed black line in Figure 7 (right) denotes the BPFO for pure rolling conditions at the given main shaft rotational speed. In this case the measured and theoretical $\mathrm{BPFO}$ are virtually on top of each other, indicating that the cage is not slipping. 

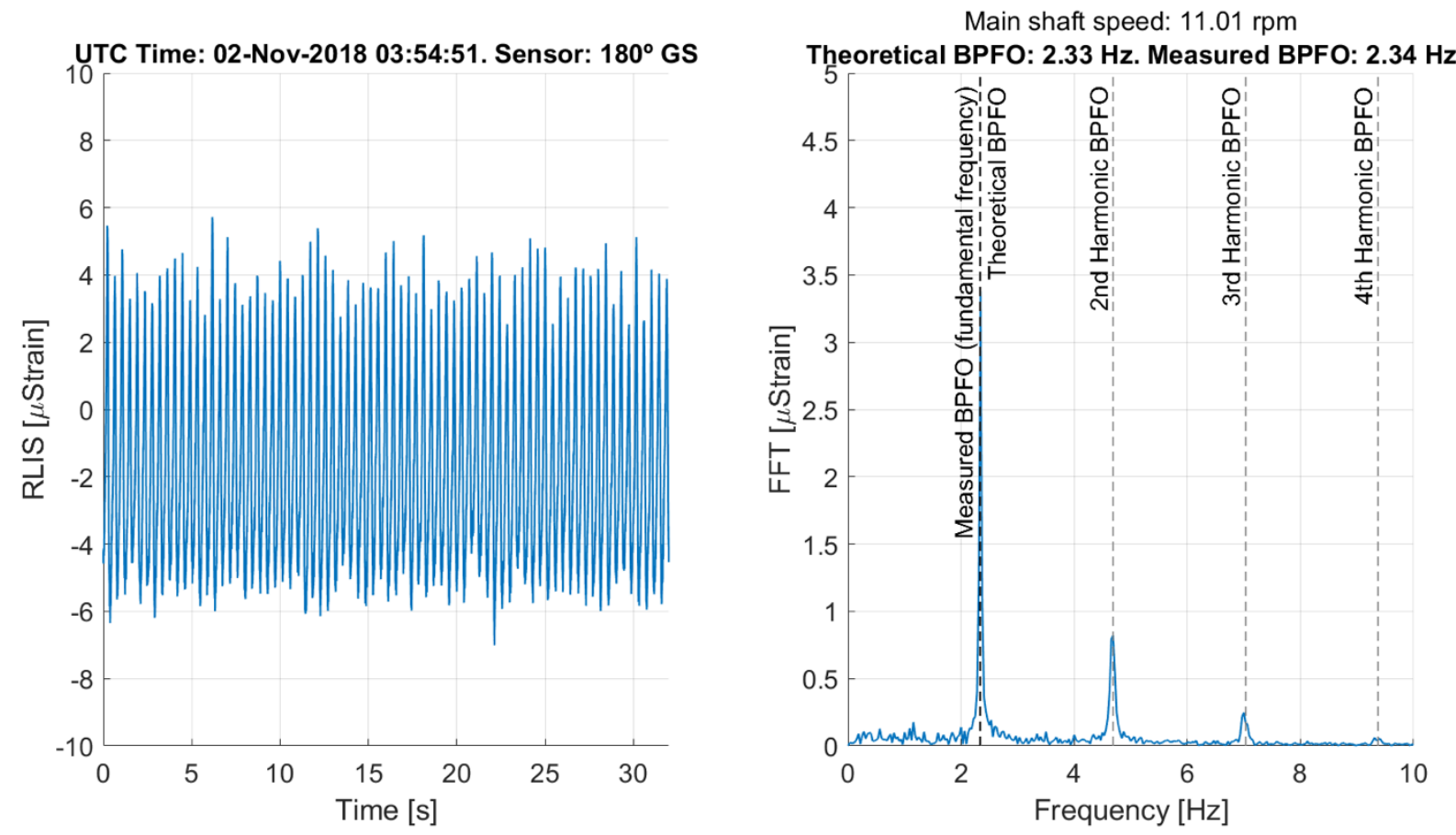

Figure 7. Example roller load-induced strain (RLIS) measurement for the $180^{\circ} \mathrm{GS}$ position in the time domain (left) and frequency domain (right) for the above cut-in condition

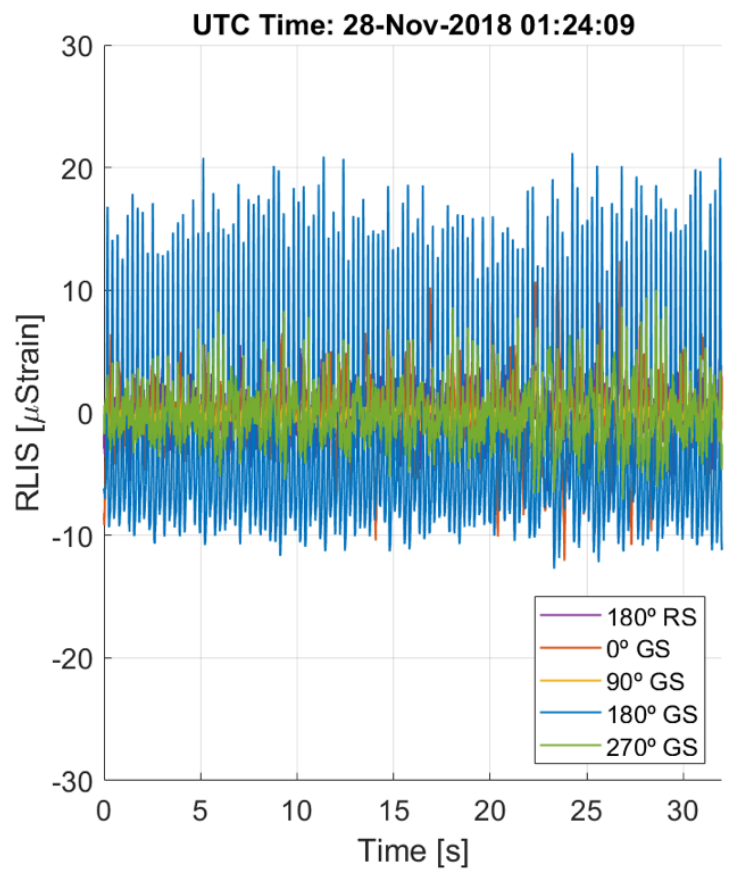

Main shaft speed: $18.30 \mathrm{rpm}$

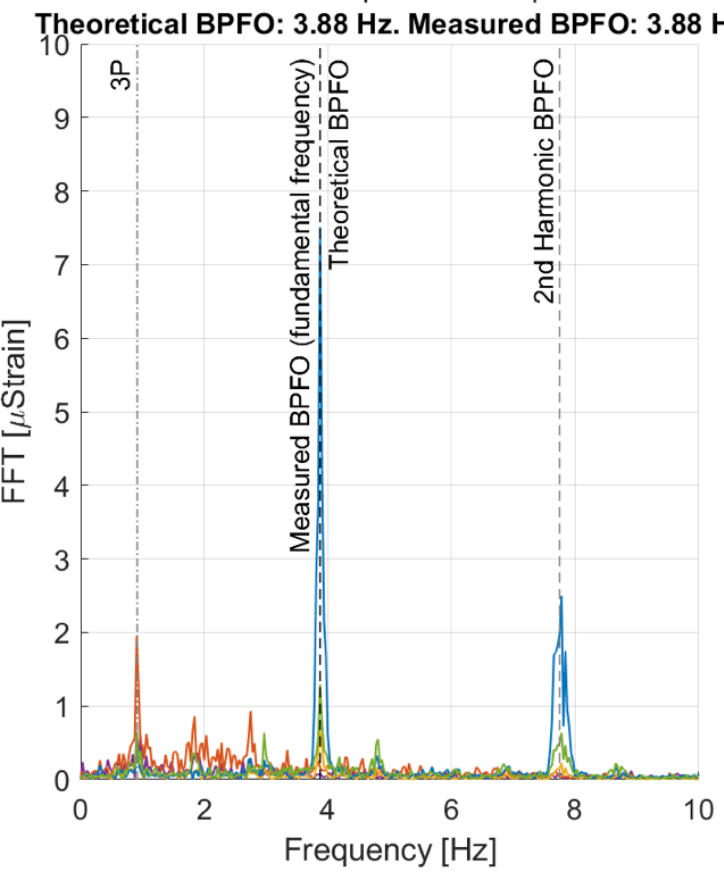

Figure 8. All roller load-induced strain (RLIS) measurements in the time domain (left) and frequency domain (right) for the rated condition

$\mathrm{BPFO}=$ ball pass frequency of the outer race, $\mathrm{FFT}=$ fast Fourier transform .

Because the bearing cage is unique, any bearing outer race location can be used to calculate the BPFO. However, using the most loaded location should result in the biggest change of strain every time that one roller passes in front of the sensor, making easier to identify the BPFO 
thanks to a better signal-to-noise ratio as Figure 8 clearly illustrates. Figure 8 shows all five RLIS measurements for the rated condition. The $180^{\circ} \mathrm{GS}$ position is still the most highly loaded as expected, and the measured BPFO is the same as the BPFO for pure rolling conditions. The other positions do not show nearly as large RLIS amplitudes, but most show the three-perrevolution (3P) blade pass excitation frequency for a three-bladed wind turbine. At this rotor speed, the $3 \mathrm{P}$ frequency is around $0.9 \mathrm{~Hz}$ and all sensors show some activity. This relatively low frequency is most evident in the $0^{\circ} \mathrm{GS}$ sensor in this case, which also shows the corresponding 6P and 9P harmonics. Having this 3P frequency in the spectrum (rather than sidebands with a 3P frequency around the BPFO frequency) denotes that the bearing housing experiences some level of deflection due to the 3P rotor loading. For reference, because of this 3P frequency the rollers will experience an amplitude modulation (e.g., sidebands around the BPFO frequency). In Figure 8 these sidebands around the BPFO occur at $2.96 \mathrm{~Hz}$ and $4.80 \mathrm{~Hz}$. The $270^{\circ} \mathrm{GS}$ sensor shows some activity at those frequencies although they are hardly noticeable in the spectrum.

\subsection{Roller Load-Induced Strain Magnitude and Tangential Strain}

A total of 3,237 acquisitions were recorded by the DVST nodes from November 1, 2018, to March 7, 2019, and used in this analysis. This relatively small, 4-month window of time is a result of some observed limitations in the associated measurements by the $180^{\circ} \mathrm{GS}$ sensor shown in Figure 9. Early measurements made by this sensor up to March 2018 were dominated by noise. Investigation of the sensor and wiring led to the conclusion that it was not properly grounded. This DVST node was then exchanged, resulting in consistent measurements from November 2018 to early March 2019. This specific sensor is located at the lower part of the GS bearing and because of the gravity and drivetrain tilt angle, it is the most likely to experience contamination from grease. It is suspected that during lengthy, summer operations in mid-2019, grease entered the contact between the strain gauge and bearing ring, consequently reducing the magnitude of the measurements. In contrast, the other sensors show consistent root-mean-square (RMS) values throughout the entire available period up to late 2019. Thus, the analysis of RLIS magnitudes and tangential strains in this report is limited to this 4-month period. 

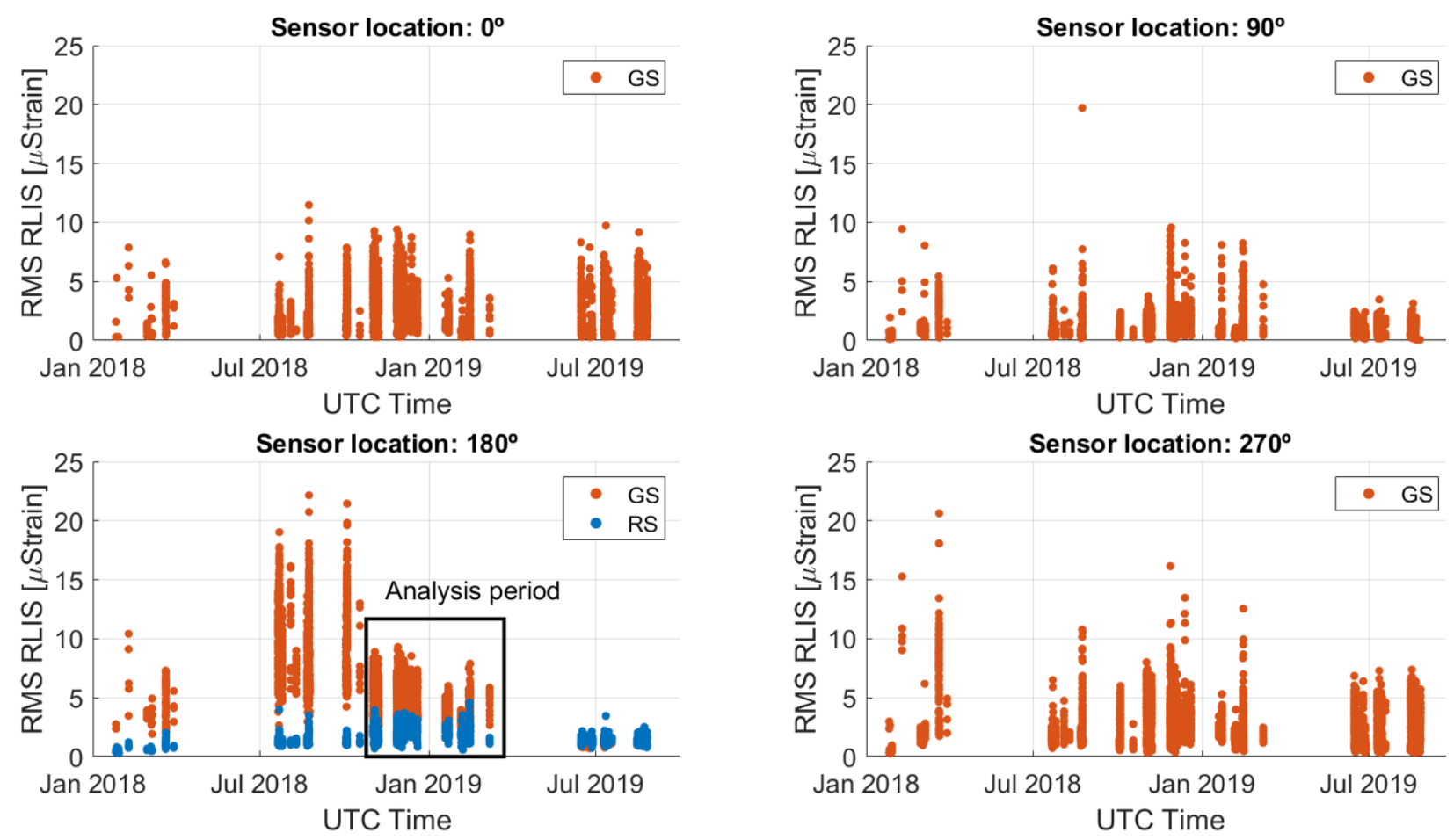

Figure 9. RMS of measured tangential strain at $0^{\circ}$ (upper left), $90^{\circ}$ (upper right), $180^{\circ}$ (lower left), and $270^{\circ}$ (lower right) circumferential positions for all available data

Further, the most desirable measurements for analysis are those that are gathered during relatively constant load and speed conditions. An additional filter was applied to limit measurements to those recorded under normal operating conditions (i.e., conditions in which the turbine is generating electrical power and main shaft rotational speeds between 11 and $18.5 \mathrm{rpm}$ ) and for main shaft speed variations less than $2 \mathrm{rpm}$. After applying these additional filters, 2,697 recordings are available. These recordings were made over a wide range of wind speeds, from just above the cut-in condition and very low power to close to the cut-out condition and above rated power. Lastly, any residual mean tangential strain was removed from the signal.

For the RLIS measurements, the RMS can be determined from the FFT by

$$
\mathrm{RMS}=\sqrt{\sum_{i=j}^{k} \frac{\left(S_{\mathrm{resp}}\left(f_{i}\right)\right)^{2}}{2}}
$$

where $S_{\text {resp }}\left(f_{i}\right)$ is the discrete FFT amplitude at frequency, $f_{i}$, and $j$ and $k$ are the indices for the first and last frequency of interest. The above expression holds true for $f_{i}>0 \mathrm{~Hz}$. Figure 10 shows the RMS of the RLIS for all five sensors that measure tangential strain for the frequency range between $75 \%$ of the theoretical BPFO and $10 \mathrm{~Hz}$ to include the corresponding RLIS dynamics. Several interesting trends can be observed in the data that correspond to expected load behavior for the bearing. The $0^{\circ}, 90^{\circ}$, and $270^{\circ} \mathrm{GS}$ positions measure very little strain until the rotor speed reaches the rated condition, whereas the $180^{\circ}$ positions measure the highest tangential strains of all sensors indicating it is the most highly loaded. The $180^{\circ} \mathrm{RS}$ position, 
though, measures very little strain. Indeed, the $0^{\circ} \mathrm{GS}$ and $180^{\circ} \mathrm{RS}$ locations are more than half of the time unloaded (the RMS in the frequency range of interest can be considered null). The $180^{\circ} \mathrm{RS}$ location is slightly loaded for low rotor thrust forces (e.g., near the cut-in region), but it's mainly unloaded when the rotor thrust force increases.
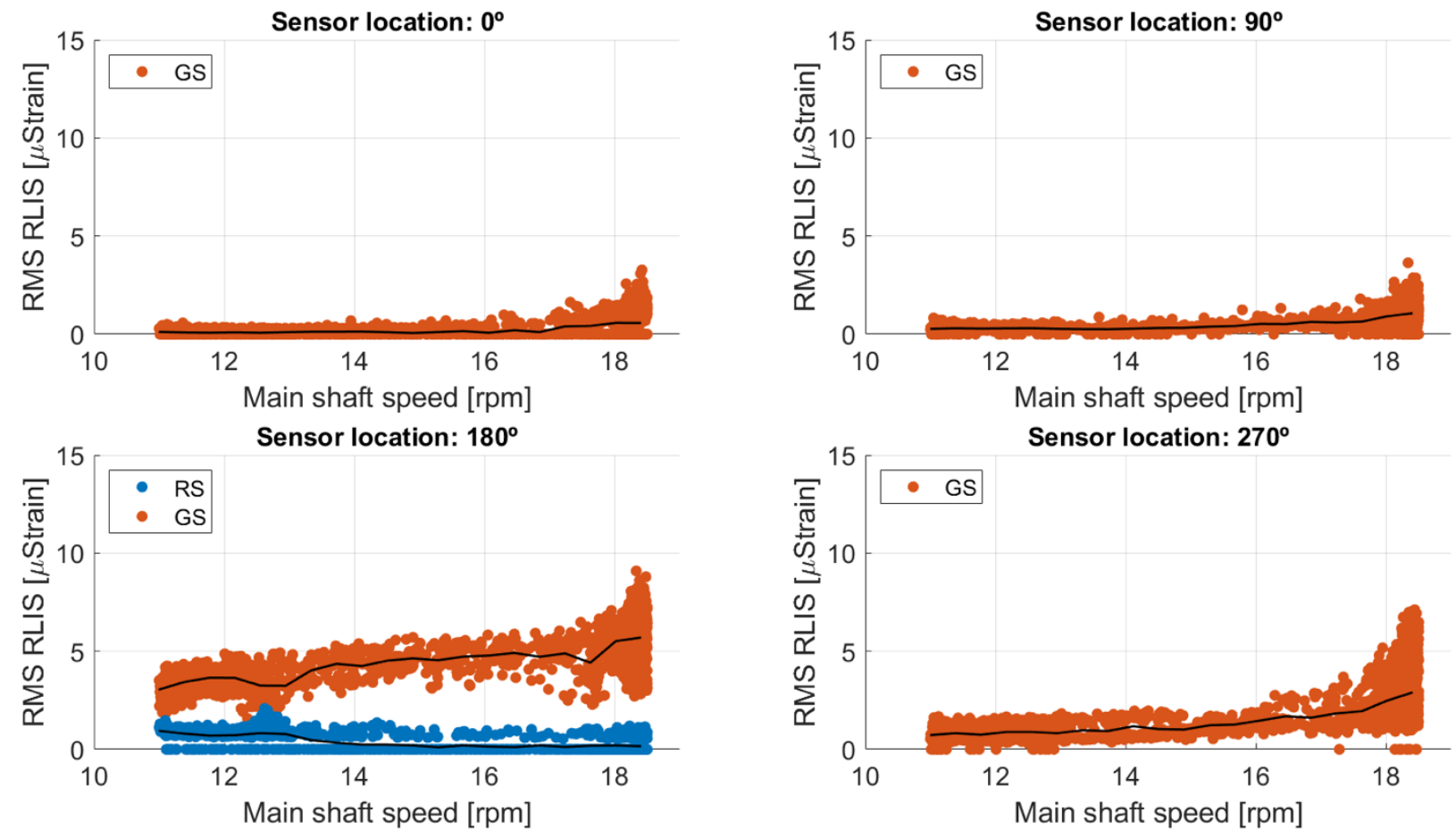

Figure 10. RMS of measured tangential strain at $0^{\circ}$ (upper left), $90^{\circ}$ (upper right), $180^{\circ}$ (lower left), and $270^{\circ}$ (lower right) circumferential positions for analyzed data 


\section{Results and Discussion}

Experimental and modeling results are presented in this section. First, the RLIS measurements are examined for any indications of cage slip. Then, the bearing load zones and contact stresses from the Transmission3D model are examined in the above cut-in and rated conditions. Finally, the tangential strains are examined using model predictions and measurements.

\subsection{Cage Slip}

A much wider range of DVST node frequency measurements can be used to determine the measured BPFO and examined for any indications of cage slip. A total of 4,604 files were recorded by the DVST nodes from January 25, 2018, to March 7, 2019. To compute the BPFO ratio, only the time waveforms recorded under normal operating conditions are considered (i.e., shaft rotational speeds between 11 and $18.5 \mathrm{rpm}$ ). In addition, since the measured and theoretical BPFO depend on the rotational speed, only time waveforms with speed variations less than or equal to $2 \mathrm{rpm}$ are included. After applying these filters, 3,818 recordings are available. Note that the window of time used in this case, more than 1 year, is larger than the one used to compute the strain magnitudes.

The ratio of the measured $\mathrm{BPFO}$ to the $\mathrm{BPFO}$ for pure rolling conditions can be calculated following the procedure described in Section 4.1. Figure 11 shows the resultant BPFO ratio for the $180^{\circ} \mathrm{GS}$ position. All the BPFO ratios are within $4.6 \%$ of the ideal ratio of 1 . The small difference is mainly caused by two effects. First, the rotor speed naturally varies over the $32 \mathrm{~s}$ period of time. The greater the variation in speed, the less defined the BPFO peak generally is. Second, the frequency resolution in the spectrum introduces slightly higher uncertainty for the BPFO ratios at lower rotational speeds than at higher rotational speeds. For example, at $11 \mathrm{rpm}$ the theoretical BPFO is $2.33 \mathrm{~Hz}$ and the frequency resolution of $0.0312 \mathrm{~Hz}$ will return BPFO ratios ranging between 0.987 and 1.013. Based on the results in Figure 11, the measured bearing cage speed is very closely aligned with the theoretical value and thus the main bearing cage is not slipping in any of the measured conditions.

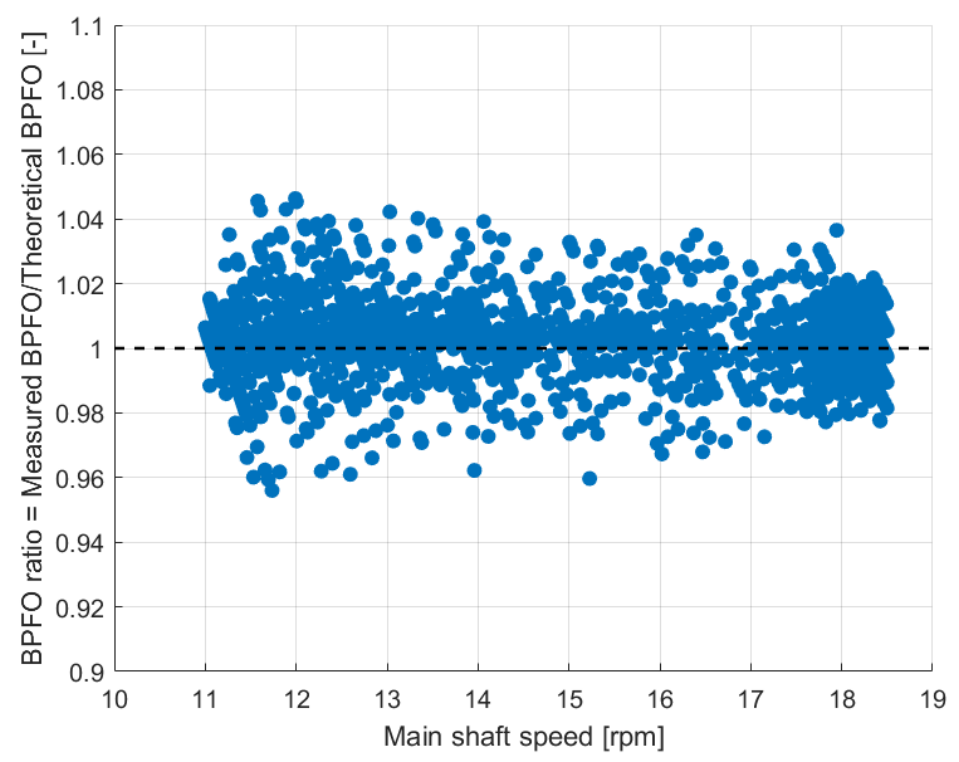

Figure 11. BPFO ratio for the $180^{\circ} \mathrm{GS}$ position 


\subsection{Load Zones and Contact Stresses}

Predicted bearing load zones and contact stresses in above cut-in and rated conditions are shown in Figure 12. Because only axial and radial loads are applied, the load zones and contact stresses are symmetric as expected. The rotor weight dominates the loading behavior, so the rollers experience the highest load and contact stress at the $180^{\circ} \mathrm{GS}$ position. The maximum load and contact stress do not change appreciably between the above cut-in and idling conditions; however, there are significant differences in loading behavior between the GS and RS rows.

In general, the GS row carries much more load than the RS row because of the applied gravity and rotor thrust loads as shown in Figure 12 (left). All GS rollers are loaded in the rated condition, with the highest roller load being $81 \mathrm{kN}$, whereas none of the RS rollers are loaded. In the above cut-in condition, the model shows a reasonable amount of load sharing by the bearing rows. Both rows have a load zone that spans approximately one-fourth of the bearing circumference in this condition.

Figure 12 (right) shows the corresponding contact stresses of both bearing rows under these two conditions. In the rated condition, the maximum contact stress of 2 gigapascals (GPa) takes place at the $180^{\circ} \mathrm{GS}$ position, whereas the minimum contact stress of $0.8 \mathrm{GPa}$ occurs at the $0^{\circ} \mathrm{GS}$ position. The contact stresses do not reduce much in the above-cut-in condition with a maximum contact stress of $1.9 \mathrm{GPa}$.

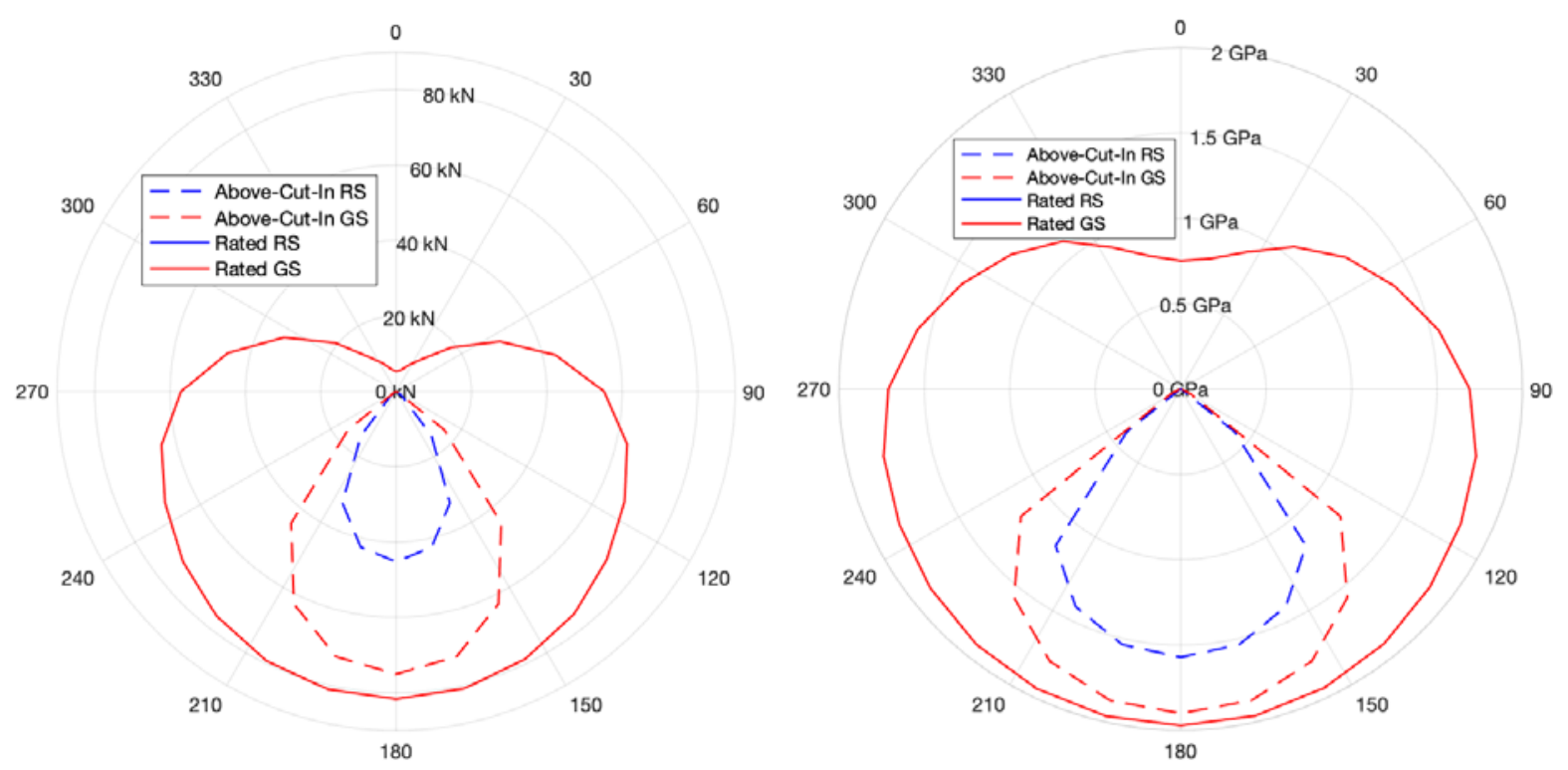

Figure 12. Bearing load zones (left) and contact stresses (right) in the above cut-in and rated conditions

\subsection{Tangential Strain}

The predicted and measured tangential strains for all locations under the two operating conditions are compared in Figure 13. Because the gauges measure strain based on the friction between the contacting surfaces instead of a bonded connection, the correlation between the experimental measurements and modeling predictions should be evaluated in a qualitative way. Overall, the agreement is reasonably good, given the simplicity of assumed steady-state loading conditions, nature of the contact (rather than bonded) strain gauge, and the exclusion of the 
bedplate flexibility in the Transmission3D model. The measured strain is $1 / 2$ to $1 / 3$ of the modeled strain, which might be expected for a friction contact strain gauge.

The relative strain amplitudes at the various circumferential locations have the same pattern as the bearing loads, as expected. The strain is consistently highest at the $180^{\circ} \mathrm{GS}$ position because of the applied axial and radial gravity load. The $180^{\circ} \mathrm{RS}$ position does record some strain and bear some load in the above cut-in condition but not the rated condition. The predicted strains at $90^{\circ}$ and $270^{\circ}$ are approximately $1 / 2$ of those at the $180^{\circ} \mathrm{GS}$ position in the rated condition, but are negligible in the above-cut-in condition. A small amount of strain is still predicted at the $90^{\circ}$ and $270^{\circ} \mathrm{GS}$ positions as a result of ring deformation, even though the nearby rollers are not loaded, as shown in Figure 5.
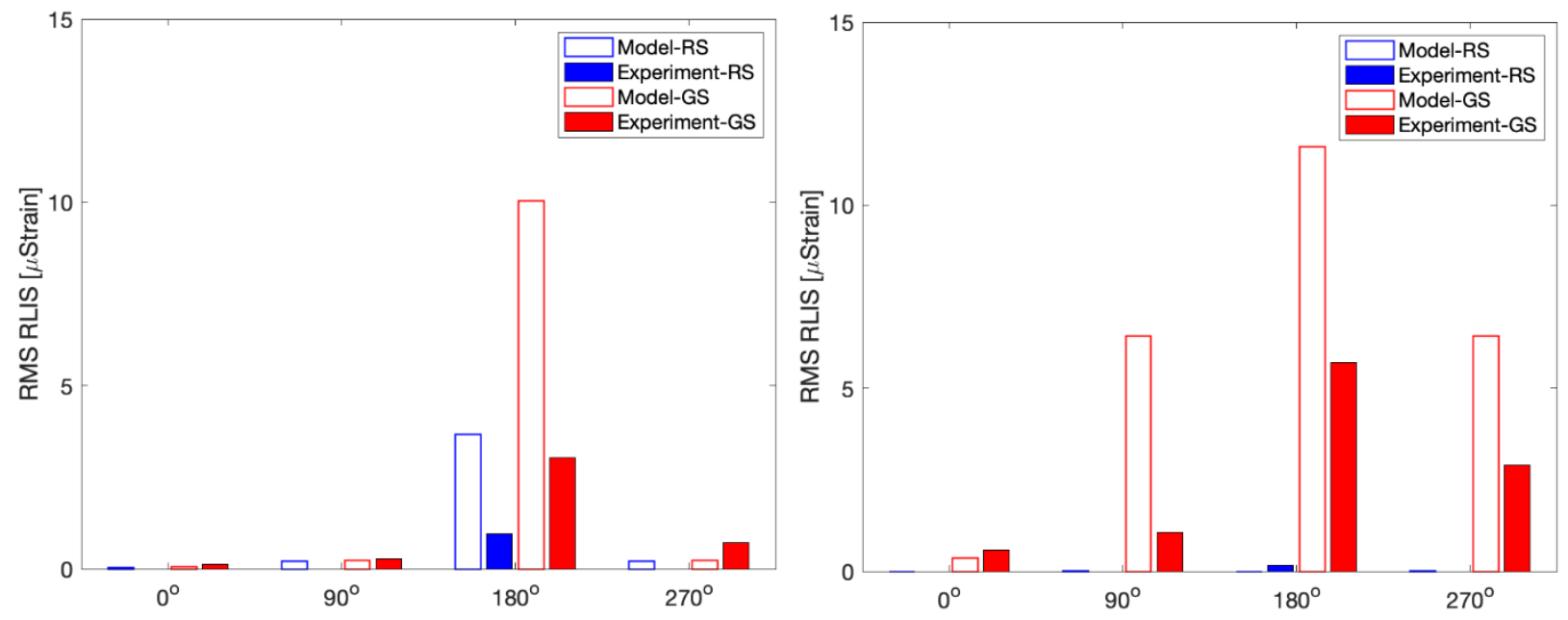

Figure 13. Tangential strains in above cut-in (left) and rated (right) conditions 


\section{Conclusions}

This report described roller load and speed characteristics of an SRB in the main bearing position of a three-point mount wind turbine drivetrain. We instrumented a commercial wind turbine to measure load characteristics on the outer ring of the bearing, and the load characteristics were used to examine the outer ring strains and cage slip in a range of operational states. Further, a simple analytic model estimated the bearing loads, which were used as input conditions to a three-dimensional finite element model. The finite-element roller load, strain, and stress results were compared to the measurements, and contact stresses were also described.

The measurements showed no evidence of cage slip. However, some amount of roller slip is expected when the rollers are outside the load zone. The predicted outer ring tangential strains correlate to the experimental data reasonably well, despite the simplicity of the assumed steadystate loading conditions, the nature of the friction-contact strain gauge, and the exclusion of the bedplate flexibility in the model. The GS row always supports more load and has a wider load zone than the RS row as a result of axial gravity and aerodynamic rotor thrust loads. The GS row will therefore consume its rating life much faster than the RS row.

In the future, we will study the acoustic emission measurements from the DVST nodes. This signal can inform whether there is asperity contact between the rollers and raceway in which wind turbine operates. We will also examine bearing temperatures and stray electrical currents to understand the failure mechanisms of main bearings. 


\section{References}

Advanced Numerical Solutions. 2021. Transmission3D. http://ansol.us/Products/TX3/.

Brake, D. 2013. "WTG SRB Main Bearing Failures." Presented at UVIG Wind Turbine/Plant Operations \& Maintenance Users Group Meeting.

Carroll, J., A. McDonald, I. Dinwoodie, D. McMillan, M. Revie, and I. Lazakis. 2017. "Availability, Operation and Maintenance Costs of Offshore Wind Turbines With Different Drive Train Configurations." Wind Energy 20(2): 361-378. 10.1002/we.2011.

Chovan, C. and A. J. Fierro. 2021. Improving Bearing Life in Wind Turbine Main Shafts and Gearboxes. The Timken Company. https://www.timken.com/resources/timken-tdi-bearingswhite-paper-improving-bearing-life-in-wind-turbine-main-shafts-and-gearboxes/.

Gould, B., N. Demas, R. Erck, M. C. Lorenzo-Martin, O. Ajayi, and A. Greco. 2021. "The Effect of Electrical Current on Premature Failures and Microstructural Degradation in Bearing Steel." International Journal of Fatigue 145: 106078. 10.1016/j.ijfatigue.2020.106078.

Gould, B., N. Demas, R. Erck, and A. Greco. 2021. Advances in Accelerated Testing for Wind Turbine Reliability. Presented at the Drivetrain Reliability Collaborative Meeting. Feb 16, 2021. https://app.box.com/s/gt8evbfr4uj8ljleasf38oc7shlufr98.

Greco, A., S. Sheng, J. Keller, and A. Erdemir. 2013. "Material Wear and Fatigue in Wind Turbine Systems.” Wear 302: 1583-1591. 10.1016/j.wear.2013.01.060.

Guo, Y. and J. Keller. 2018. "Investigation of High-Speed Shaft Bearing Loads in Wind Turbine Gearboxes through Dynamometer Testing." Wind Energy 21(2): 139-50. 10.1002/we.2150.

Guo, Y., O. Bankestrom, R. Bergua, J. Keller, and M. Dunn. 2021. "Investigation of Main Bearing Operating Conditions in a Three-Point Mount Wind Turbine Drivetrain." Forschung im Ingenieurwesen. 10.1007/s10010-021-00477-8.

Hart, E. 2020. "Developing a Systematic Approach to the Analysis of Time-varying Main Bearing Loads for Wind Turbines." Wind Energy 23(12): 2150-2165. 10.1002/we.2549.

Hart, E., A. Turnbull, J. Feuchtwang, D. McMillan, E. Golysheva, and R. Elliott. 2019. "Wind Turbine Main-Bearing Loading and Wind Field Characteristics." Wind Energy 22(11): 1534 1547. $10.1002 /$ we. 2386.

Hart, E., B. Clarke, G. Nicholas, A. Kazemi Amiri, J. Stirling, J. Carroll, R. Dwyer-Joyce, A. McDonald, and H. Long. 2020. "A Review of Wind Turbine Main Bearings: Design, Operation, Modelling, Damage Mechanisms and Fault Detection." Wind Energy Science 5: 105-124. 10.5194/wes-5-105-2020.

James, P. 2018. Optimized Spherical Roller Bearing for Wind Turbine Rotors. Presented at the Drivetrain Reliability Collaborative Meeting. Feb 21, 2018. 
https://www.dropbox.com/s/1vu6t47fovgaysh/03\%20Optimized\%20Spherical\%20Roller\%20Be aring.pdf? $\mathrm{dl}=0$.

Keller, J. 2018. Investigating Main and High-Speed Shaft Bearing Reliability Through Uptower Testing. Golden, CO: National Renewable Energy Laboratory. NREL/PR-5000-70958. http://www.nrel.gov/docs/fy180sti/70958.pdf.

Keller, J., Y. Guo, and L. Sethuraman. 2019. Uptower Investigation of Main and High-SpeedShaft Bearing Reliability. Golden, CO: National Renewable Energy Laboratory. NREL/TP-500071529. http://www.nrel.gov/docs/fy19osti/71529.pdf.

Keller, J., Y. Guo, Z. Zhang, and D. Lucas. 2018. "Comparison of Planetary Bearing Loadsharing Characteristics in Wind Turbine Gearboxes." Wind Energy Science 3: 947-960. 10.5194/wes3-947-2018.

Keller, J. and S. Lambert. 2018. Gearbox Instrumentation for the Investigation of Bearing Axial Cracking. Golden, CO: National Renewable Energy Laboratory. NREL/TP-5000-70639. http://www.nrel.gov/docs/fy18osti/70639.pdf.

Keller, J., S. Sheng, Y. Guo, B. Gould, and A. Greco. 2021. Wind Turbine Drivetrain Reliability and Wind Plant Operations and Maintenance Research and Development Opportunities. Golden, CO: National Renewable Energy Laboratory. NREL/TP-5000-80195. http://www.nrel.gov/docs/fy21osti/80195.pdf.

Kotzalas, M.N. and G.L. Doll. 2010. "Tribological Advancements for Reliable Wind Turbine Performance." Philosophical Transactions of the Royal Society A 368: 4829-4850. $\underline{10.1098 / \text { rsta.2010.0194. }}$

Liang, Y., An, Z., Liu, B. 2013. "Fatigue life prediction for wind turbine main shaft bearings." In: International Conference on Quality, Reliability, Risk, Maintenance, and Safety Engineering. 888-893. 10.1109/QR2MSE.2013.6625711.

Nejad, A.R., J. Keller, Y. Guo, S. Sheng, H. Polinder, S. Watson, J. Dong, Z. Qin, A. Ebrahimi, R. Schelenz, et al. 2021. "Wind Turbine Drivetrains: State-of-the-Art Technologies and Future Development Trends." Wind Energy Science Discussions [preprint] 10.5194/wes-2021-63.

Raju, D. and O. Bankestrom. 2017. "A System Approach to Address Main Bearing Reliability." Presented at the Drivetrain Reliability Collaborative Meeting. Feb. 21, 2018.

Santos, R., and J. van Dam. 2015. Mechanical Loads Test Report for the U.S. Department of Energy 1.5-Megawatt Wind Turbine. Golden, CO: National Renewable Energy Laboratory. NREL/TP-5000-63679. http://www.nrel.gov/docs/fy15osti/63679.pdf.

Sethuraman, L., Y. Guo, and S. Sheng, S. 2015. Main Bearing Dynamics in Three-Point Suspension Drivetrains for Wind Turbines. Golden, CO: National Renewable Energy Laboratory. NREL/PR-5000-64311. http://www.nrel.gov/docs/fy15osti/64311.pdf. 
SKF. 2021. "240/600 BC Spherical roller bearings - SKF Explorer."

https://www.skf.com/us/products/rolling-bearings/roller-bearings/spherical-rollerbearings/productid- $240 \% 2 \mathrm{~F} 600 \% 20 \mathrm{BC}$.

Stehly, T., P. Beiter, and P. Duffy. 2020. 2019 Cost of Wind Energy Review. Golden, CO: National Renewable Energy Laboratory. NREL/TP-5000-78471. https://www.nrel.gov/docs/fy21osti/78471.pdf.

Wiser, R., M. Bolinger, and E. Lantz. 2019. "Assessing Wind Power Operating Costs in the United States: Results From a Survey of Wind Industry Experts.” Renewable Energy Focus 30: 46-57. 10.1016/j.ref.2019.05.003. 